\begin{tabular}{l|l|l} 
Jurnal Kependidikan Dasar & Volume. 2 \\
& Nomor.2 \\
\hline Islam Berbasis Sains & Tahun.2017 \\
\hline
\end{tabular}

\title{
Program Pembelajaran IPA Berbasis Masalah untuk Menumbuhkan Metakognisi Siswa MTS di Salatiga
}

\author{
Anggun Zuhaida \\ IAIN Salatiga \\ Surel : anggunchemist@gmail.com
}

\begin{abstract}
Abstrak
Perkembangan bahan kajian tentang IPA yang pesat menuntut para pendidik agar mampu merancang dan melaksanakan pendidikan yang lebih terarah pada pengusaan konsep IPA. Perkembangan IPA tidak hanya ditunjukkan oleh kumpulan fakta, melainkan timbul akibat adanya metode ilmiah dan sikap ilmiah. IPA tidak hanya sekedar pengetahuan, melainkan melibatkan operasi mental, keterampilan dan strategi dalam menemukan konsep IPA itu sendiri. Program pembelajaran IPA berbasis masalah untuk menumbuhkan metakognisi merupakan pelaksanaan perangkat pembelajaran, khususnya silabus, RPP, lembar kerja, media, dan asesmen. Model pembelajaran yang dipakai dalam penelitian ini adalah model problem based learning (PBL). Inovasi model pembelajaran merujuk pada penggunaan model PBL dalam pelaksanaan pembelajaran yang digunakan untuk mengetahui pencapaian metakognisi. Secara umum, penelitian ini dilakukan dengan prosedur penelitian Research \& Development. Penelitian dilakukan pada MTs di Kota Salatiga dengan subjek penelitian siswa kelas VIII dengan cara pengambilan sampling yaitu purposive sampling. Tujuan akhir dari penelitian ini adalah untuk meninjau karakteristik Program Pembelajaran IPA berbasis masalah, serta menganalisis tingkat pencapaian kemampuan metakognisi. Indikator-indikator metakognisi yang digunakan adalah mengacu pada tipe-tipe Metakognisi Schraw dan Dennison (1994:472-474). Hasil pencapaian keterampilan metakognisi pada aspek tes essay menunjukkan hasil yang positif, aspek kinerja menunjukkan indikator yang dominan adalah planning, sedangkan dari hasil angket menunjukkan dominasi indikator evaluasi.
\end{abstract}

Kata Kunci:, pembelajaran IPA, problem based learning, metakognisi

\begin{abstract}
The rapid development of study materials on science requires educators to be able to design and implement more targeted education on the concept of science. The development of science is not only shown by a collection of facts, but arises due to the existence of scientific methods and scientific attitudes. Science is not just about knowledge, it involves mental operations, skills and strategies in discovering the concept of science itself. Science-problem based learning program for metacognition for metacognition skills development is a implementation of learning tools, especially syllabus, lesson plan (RPP), worksheet, media, and assessment. Learning model used in this research is problem based learning (PBL).
\end{abstract}


Learning innovation model refers to PBL model in learning implementation to know student metacognition achievement. The research methode is Research and Development Procedure (R\&D). The research was conducted on MTs in Salatiga City with the subject of the study of students in $8^{\text {th }}$ class by purposive sampling method. The research final goal is to review characteristic of problem-based science learning program and to analyze achievment of metacognition ability level. Metacognition indicators used are referring to the types of Schraw and Dennison Metacognition (1994: 472-474). Result of metacognition skill achievement on aspect of essay test showed positive result, performance aspect showed the dominant indicator was planning, meanwhile from result of questionnaire showed dominance of evaluation indicator

Keywords: science learning, problem based learning, metacognition

\section{A. PENDAHULUAN}

Pembelajaran IPA merupakan salah satu model implementasi kurikulum yang dianjurkan untuk diaplikasikan di jenjang pendidikan dasar yaitu SD dan SMP. Pelaksanaan pembelajaran IPA membutuhkan profe-sionalisme guru yang memadai. Guru harus memiliki cukup ilmu dalam menyampaikan pengetahuan IPA serta diperlukan suatu sarana yang berupa model pembelajaran beserta perangkat pembelajaran yang sesuai. $^{1}$

Perkembangan bahan kajian tentang IPA yang pesat menuntut para pendidik agar mampu merancang dan melaksanakan pendidikan yang lebih tera-rah pada pengusaan konsep IPA. IPA merupakan gabungan dari beberapa ilmu, antara lain biologi, fisika dan ki-mia. Perkembangan IPA tidak hanya ditunjukkan oleh kumpulan fakta, melainkan timbul akibat adanya metode ilmiah dan sikap ilmiah. IPA tidak hanya sekedar pengetahuan, melainkan meli-batkan

\footnotetext{
${ }^{1}$ Putri Rahayu, S. Mulyani, and S. S. Miswadi, "Pengembangan Pembelajaran IPA Terpadu Dengan Menggunakan Model Pembelajaran Problem Base Melalui Lesson Study," Jurnal Pendidikan IPA Indonesia 1, no. 1 (2012).
}

operasi mental, keterampilan dan strategi dalam menemukan konsep IPA itu sendiri.

Pembelajaran IPA masih diajarkan meniru pada paradigma pen=didikan lama "teacher centered". Konsep dari guru diberikan kepada siswa dan siswa menerima begitu saja sehingga siswa tidak paham untuk apa IPA dipelajari. Sehingga siswa tidak dapat menerapkan konsep yang siswa dapat di lingkungannya. Siswa hanya menerima konsep IPA saja tetapi jika diberi soal aplikatif dengan apa yang diajarkan gurunya maka siswa merasa kesulitan untuk mengerjakannya. Pem-belajaran IPA dewasa ini masih dia-jarkan secara terpisah dan tidak sesuai dengan tuntutan kurikulum, sehingga perlu adanya suatu model pembelajaran keterpaduan ${ }^{2}$.

Metakognisi berasal dari kata meta yang artinya setelah, melebihi dan di atas, sedangkan kognisi diartikan sebagai apa yang diketahui serta dipikirkan oleh

\footnotetext{
${ }^{2}$ Irsad Rosidi, "PENGEMBANGAN PERANGKAT PEMBELAJARAN IPA TERPADU TIPE INTEGRATED UNTUK MENGETAHUI KETUNTASAN BELAJAR IPA SISWA SMP PADA TOPIK PENGELOLAAN LINGKUNGAN," Jurnal Pena Sains 2, no. 1 (2015): 14-25.
} 
seseorang atau yang mencakup keterampilan yang berhu-bungan dengan proses berfikir. Metakognisi dapat didefinisikan sebagai "berpikir tentang berpikir", metakognisi mengacu pada kesadaran peserta didik terhadap kemampuan yang dimilikinya serta kemampuan untuk memahami, mengontrol dan memanipulasi proses-proses kognitif yang mereka miliki Flavell dalam Weinert \& Kluwe ${ }^{3}$ dan Downing ${ }^{4}$.

Pengembangan metakognisi penting dilakukan, karena metakognisi adalah kunci dalam pencapaian pemahaman suatu materi pelajaran agar lebih bermakna dan lebih tahan lama. Calon guru, diharuskan untuk dapat melatih metakognisinya agar dapat mengelola pembelajarannya kelak. Metakognisi siswa dapat ditumbuhkan salah satunya melalui suatu program pembelajaran yang kurikulumnya dikembangkan sesuai dengan tujuan yang dikehendaki. Program pembelajaran khususnya pada program pem-belajaran IPA Terpadu Berkarakter dirancang dengan suatu pelaksanaan pembelajaran dengan menggunakan model pembelajaran berbasis masalah (Problem Based Learning) yang diharapkan dapat menumbuhkan mata-kognisi dan menstimulasi peserta didik untuk melakukan kegiatan dalam rangka meningkatkan kemampuan individual dengan mengaplikasikan ke-mampuan

\footnotetext{
${ }^{3}$ John H. Flavell, "Speculations about the Nature and Development of Metacognition," in Metacognition, Motivation, and Understanding (London: Lawrence Erbaum Associates, 1987), 21-29.

${ }^{4}$ Kevin Downing, "Problem-Based Learning and Metacognition," Asian Journal Education \& Learning 1 (2010): 75-96.
}

dan pengetahuan dalam kehi-dupan sehari-hari.

Dengan merujuk berbagai hal yang telah dipaparkan, disusunlah suatu program pembelajaran IPA berbasis masalah untuk menumbuhkan keterampilan metakognisi. Program ini merupakan serangkaian porses pembelajaran yang meliputi semua pe-rangkat pembelajaran, khususnya silabus, RPP, lembar kerja, media, dan asesmen sebagaimana diatur dalam permendiknas No. 41 Tahun 2007.

\section{B. METODE PENELITIAN}

Metode penelitian yang digunakan dalam penelitian ini adalah Research and Development hasil adap-tasi, yang terbagi dalam beberapa tahapan yaitu 1) define, 2) design, 3) develop dan 4) implementasi mo-del/validasi model.

Penelitian dilakukan pada MTs di Kota Salatiga dengan subjek penelitian para siswa kelas VIII dengan cara pengambilan sampling yaitu purposive sampling. Data yang diperoleh pada penelitian ini terdiri dari data kualitatif dan data kuantitatif. Data kualitatif berupa: 1) hasil pengukuran kemam-puan metakognisi siswa pada materi IPA; 2) penjelasan karakteristik pem-belajaran IPA berbasis masalh. Data kualitatif tersebut dianalisis secara deskriptif kualitatif. Data kuantitatif be-rupa peningkatan kemampuan me-takognisi siswa. 


\section{HASIL PENELITIAN DAN PEMBAHASAN}

\section{Karakteristik Program Pembelajaran Sains Berbasis Masalah untuk Menumbuhkan Metakognisi}

Program pembelajaran ini menggunakan menggunakan model pembelajaran PBL. Pembelajaran berbasis masalah adalah metode pengajaran yang menggunakan perma-salahan yang terstruktur sebagai konteks bagi peserta didik untuk memperoleh keterampilan pemecahan masalah dan pengetahuan dasar ${ }^{5}$. Pembelajaran berbasis masalah adalah cara belajar yang mendorong pema-haman lebih dalam dari suatu materi, dan juga merupakan pembelajaran berorientasi masalah di mana peserta didik tidak hanya mendapatkan penge-tahuan dasar, tetapi juga dapat mengalami bagaimana menggunakan pengetahuan mereka untuk meme-cahkan masalah dalam dunia nyata. Selain itu tujuan pembelajaran berbasis masalah adalah meningkatkan kemam-puan peserta didik untuk bekerja dalam tim, menunjukkan kemampuan koor-dinasi mereka untuk mengakses infor-masi dan mengubahnya menjadi suatu pengetahuan yang layak. Pembelajaran berbasis masalah juga bertujuan untuk membantu peserta didik mengembangkan kemampuan higher order thinking dan substansial dasar suatu disiplin pengetahuan dengan menempatkan mahasiswa berperan aktif

\footnotetext{
${ }^{5}$ Anggun Zuhaida, "PENGEMBANGAN ASESMEN METAKOGNISI CALON GURU IPA MELALUI PEMBELAJARAN BERBASIS MASALAH," JURNAL PENELITIAN 12, no. 2 (2015): 213-22.
}

dalam praktik yang dihadapkan dengan situasi yang mencerminkan dunia nyata.

Karakteristik dalam Pembe-lajaran Berbasis Masalah menurut Akinoglu dan Tandogan ${ }^{6}$ adalah:

1. Proses Belajar harus dimulai dengan masalah, terutama masalah yang jelas penting/masih belum terpecahkan.

2. Isi dan praktek harus menyertakan situasi yang menarik perhatian peserta didik.

3. Guru hanya menjadi pemandu dalam kelas.

4. Peserta didik harus diberikan waktu yang diperlukan untuk berpikir atau mengumpulkan informasi dan mengatur strategi mereka dalam pemecahan masalah, dan pikiran kreatif mereka harus didorong dalam proses ini.

5. Kesulitan subjek penting untuk menjadi belajar tidak harus pada tingkat tinggi yang bisa mencegah peserta didik.

6. Sebuah belajar yang nyaman, santai dan lingkungan aman harus ditetapkan untuk mengembangkan kemampuan peserta didik pada pemikiran dan pemecahan masalah mereka sendiri.

Karakteristik dari skenario pembelajaran yang merupakan alat dasar dalam pendidikan berbasis masalah menurut Akinoglu dan Tandogan ${ }^{7}$ adalah:

1. Masalah harus dipilih mana yang paling pas dengan dunia nyata

\footnotetext{
${ }^{6}$ Ruhan Ozkardes Tandogan and Akinoglu Orhan, "The Effects of Problem-Based Active Learning in Science Education on Students' Academic Achievement, Attitude and Concept Learning.," Online Submission 3, no. 1 (2007): 71-81.

${ }^{7}$ Tandogan and Orhan.
} 
2. Soal/masalah harus open ended.

3. Harus membangkitkan rasa penasaran.

4. Harus fokus hanya pada satu masalah.

5. Harus mengajarkan perilaku dan etika yang baik,

6. Harus membantu peserta didik untuk merefleksikan secara bebas dan mengekspresikan diri mereka sendiri.

7. Dengan membuat personifikasi cocok, peserta didik diberi kesem-patan untuk merawat masalah seolah-olah itu masalah mereka dan menjadi bersedia melakukannya.

Akinoglu dan Tandogan ${ }^{8}$ menyatakan keuntungan dari pembelajaran berbasis masalah (PBL) adalah:

1. Kelas berpusat pada peserta didik bukan berpusat pada guru.

2. Mendorong peserta didik untuk belajar bahan dan konsep baru ketika memecahkan masalah.

3. Mengembangkan keterampilan pemecahan masalah peserta didik.

4. Pembelajaran ini mengembangkan model pengendalian diri pada peserta didik. Hal itu mengajarkan kepada peserta didik untuk membuat rencana yang prospektif, menghadapi realita yang ada dan mengekspresikan emosi.

5. Model ini memungkinkan peserta didik untuk melihat peristiwa multidimensi dan dengan perspektif yang lebih dalam.

6. Mengembangkan kemampuan tingkat sosialisasi dan komunikasi pada peserta didik dengan memungkinkan

\footnotetext{
${ }^{8}$ Tandogan and Orhan.
}

mereka untuk belajar dan bekerja dalam tim.

7. Mengembangkan kemampuan tingkat berpikir tinggi/berpikir kritis dan berfikir ilmiah peserta didik

8. Menyatukan teori dan praktek. Hal ini memungkinkan peserta didik untuk menggabungkan penge-tahuan lama mereka dengan pengetahuan yang baru dan mengembangkan keterampilan me-reka dalam menilai lingkungan disiplin tertentu.

9. Memotivasi belajar bagi guru dan peserta didik.

10. Peserta didik memperoleh keterampilan manajemen waktu, fokus, pengumpulan data, penyu-sunan laporan dan evaluasi.

11. Membuka jalan untuk belajar seumur hidup

Akinoglu dan Tandogan ${ }^{9}$ menyatakan keterbatasan pembelajaran berbasis masalah (PBL) adalah:

1. Sulit bagi guru untuk mengubah gaya mengajar mereka

2. Memakan waktu lebih banyak bagi peserta didik untuk memecahkan situasi yang bermasalah ketika situasi ini pertama disajikan di kelas.

3. Kelompok atau individu dapat menyelesaikan karya mereka lebih awal atau kemudian.

4. Pembelajaran berbasis masalah membutuhkan kaya bahan dan penelitian.

5. Sulit untuk menerapkan pembelajaran berbasis masalah di semua kelas. Hal ini tidak bisa berhasil jika diterapkan pada peserta didik yang tidak bisa sepenuhnya

\footnotetext{
${ }^{9}$ Tandogan and Orhan.
} 
memahami nilai atau lingkup masalah dengan konten sosial.

6. Cukup sulit dalam menilai pembelajaran

Tabel 1: Sintaks Pembelajaran Berbasis Masalah Menurut Arends ${ }^{10}$

\begin{tabular}{|c|c|}
\hline FASE-FASE & PERILAKU GURU \\
\hline $\begin{array}{l}\text { Fase 1: } \\
\text { Memberikan } \\
\text { orientasi tentang } \\
\text { permasalahannya } \\
\text { kepada peserta } \\
\text { didik }\end{array}$ & $\begin{array}{l}\text { Guru membahas tujuan } \\
\text { pelajaran, } \\
\text { mendeskripsikan } \\
\text { berbagai kebutuhan } \\
\text { logistik penting, dan } \\
\text { memotivasi peserta didik } \\
\text { untuk terlibat dalam } \\
\text { kegiatan mengatasi } \\
\text { masalah }\end{array}$ \\
\hline $\begin{array}{l}\text { Fase } 2 \text { : } \\
\text { Mengorganisasikan } \\
\text { peserta didik } \\
\text { untuk meneliti }\end{array}$ & $\begin{array}{l}\text { Guru membantu peserta } \\
\text { didik mendefinisikan dan } \\
\text { mengorganisasikan } \\
\text { tugas-tugas belajar } \\
\text { terkait dengan } \\
\text { permasalahannya. }\end{array}$ \\
\hline $\begin{array}{l}\text { Fase } 3 \text { : Membantu } \\
\text { investigasi mandiri } \\
\text { dan kelompok }\end{array}$ & $\begin{array}{l}\text { Guru mendorong peserta } \\
\text { didik untuk } \\
\text { mendapatkan informasi } \\
\text { yang tepat, } \\
\text { melaksanakan } \\
\text { eksperimen, dan mencari } \\
\text { penjelasan dan solusi. }\end{array}$ \\
\hline $\begin{array}{l}\text { Fase } 4 \text { : } \\
\text { Mengembangkan } \\
\text { dan } \\
\text { mempresentasikan } \\
\text { artefak dan exhibit } \\
\text { (hasil) }\end{array}$ & $\begin{array}{l}\text { Guru membantu peserta } \\
\text { didik dalam } \\
\text { merencanakan dan } \\
\text { menyiapkan artefak- } \\
\text { artefak (hasil) yang } \\
\text { tepat, seperti laporan, } \\
\text { rekaman video, dan } \\
\text { model-model serta } \\
\text { membantu mereka untuk } \\
\text { menyampaikannya } \\
\text { kepada orang lain. }\end{array}$ \\
\hline $\begin{array}{l}\text { Fase } 5 \text { : } \\
\text { Menganalisis dan }\end{array}$ & $\begin{array}{l}\text { Guru membantu peserta } \\
\text { didik melakukan refleksi }\end{array}$ \\
\hline
\end{tabular}

${ }^{10}$ Richard Arends, Learning to Teach, trans. Helly Prajitno Soetjipto (Yogyakarta: Pustaka Pelajar, 2008).

\begin{tabular}{|l|l|}
\hline FASE-FASE & PERILAKU GURU \\
\hline $\begin{array}{l}\text { mengevaluasi } \\
\text { proses mengatasi } \\
\text { masalah }\end{array}$ & $\begin{array}{l}\text { terhadap investigasinya } \\
\text { dan proses-proses yang } \\
\text { mereka gunakan. }\end{array}$ \\
\hline
\end{tabular}

Pelaksanaan pembelajaran pada IPA Terpadu diawali dengan pemberian masalah open-ended yang harus diselesaikan oleh siswa dalam suatu kegiatan diskusi secara berkelompok. Masalah open-ended yang diberikan pada saat pembelajaran berfungsi sebagai stimulus. Diharapkan mahasis-wa nantinya akan melaksanakan tugas belajarnya yang telah dirancang pada pembelajaran berbasis masalah yaitu dapat mengembangkan keterampilan mengidentifikasi masalah, menyelesaikan masalah, mengevaluasi dan menganalisis masalah.

Tahap pembelajaran yang dilakukan mengacu pada sintaks pembelajaran berbasis masalah yang dikembangkan oleh Arends (2012:57). Sedangkan materi pembelajaran dalam penelitian ini adalah mencakup materi IPA Terpadu. Pada pembelajaran ini nantinya siswa akan diukur kemampuan metakognisinya dengan menggunakan instrumen asesmen metakognisi yang terdiri dari: asesmen diri (pada awal dan akhir pembelajaran), asesmen tes essay (awal dan akhir pembelajaran) serta asesmen sikap pada saat diskusi dan presentasi pemecahan masalah.

Pengukuran keterampilan metakognisi dilakukan dengan menggunakan beberapa asesmen, diantaranya adalah asesmen tes, observasi, dan angket yang disusun dan disesuaikan dengan indikator-indikator metakognisi. Indi- 
kator-indikator Metakognisi yang Dikembangkan mengikuti Tipe-tipe Metakognisi yang dikemukakan oleh Schraw dan Dennison ${ }^{11}$ yang meliputi beberapa keterampilan metakognisi: pengetahuan deklaratif, (b) pengetahuan prosedural, (c) pengetahuan kondisional, (d) planning, (e) manajemen informasi, (f) monitoring, (g) debugging dan (h) evaluasi.

\section{Hasil Pencapaian}

Hasil pengukuran keterampilan metakognisi dilihat dari beberapa asesmen metakognisi, diantaranya adalah tes essay, kinerja dan angket. Tes essay (uraian) disusun berdasarkan silabus dan RPP yang dikembangkan melalui pembelajaran berbasis masalah. Tes essay terdiri dari 20 butir soal.

Berdasarkan analisis $\mathrm{N}$-gain diperoleh hasil 0,5 (kategori sedang). Pada tes essay perubahan ketercapaian indikator metakognisi peserta didik dapat dilihat secara keseluruhan dengan menggunakan angka kategori. Angka kategori terdiri dari: angka 5 dan 4 menunjukkan indikator tercapai (IT), angka 3 menunjukkan sebagian besar indikator tercapai (SBIT), angka 2 menunjukkan sebagian kecil indikator tercapai (SKIT) dan angka 1 dan 0 menunjukkan tidak mencapai indikator metakognisi (TMI). Pengkategorian angka tersebut dimodifikasi dari Standard Grade Arrangement in Science. Hasil analisis pengkategorian perubahan ketercapaian

\footnotetext{
${ }^{11}$ Zuhaida, "PENGEMBANGAN ASESMEN METAKOGNISI CALON GURU IPA MELALUI PEMBELAJARAN BERBASIS MASALAH."
}

indikator metakognisi peserta didik dapat dilihat pada data berikut:

Tabel 2. Hasil Pencapaian Metakognisi Pra dan Pasca Pembelajaran

\begin{tabular}{|l|c|c|}
\hline \multicolumn{1}{|c|}{ KATEGORI } & $\begin{array}{c}\text { \% PRA } \\
\text { PEMBELAJA- } \\
\text { RAN }\end{array}$ & $\begin{array}{c}\text { \% PASCA } \\
\text { PEMBELAJA- } \\
\text { RAN }\end{array}$ \\
\hline $\begin{array}{l}\text { Indikator } \\
\text { Tercapai }\end{array}$ & - & $49 \%$ \\
\hline $\begin{array}{l}\text { Sebagian } \\
\text { besar } \\
\text { indikator } \\
\text { tercapai }\end{array}$ & - & $31 \%$ \\
\hline $\begin{array}{l}\text { Sebagian } \\
\text { kecil } \\
\text { indikator } \\
\text { tercapai }\end{array}$ & $30 \%$ & $20 \%$ \\
\hline $\begin{array}{l}\text { Tidak } \\
\text { mencapai } \\
\text { indikator } \\
\text { metakognisi }\end{array}$ & $70 \%$ & 0 \\
\hline
\end{tabular}

Berdasarkan tabel tersebut diketahui bahwa porsi TMI pasca pembelajaran tidak ada. Hal ini menunjukkan adanya perbedaan kemampuan yang signifikan dari peserta didik. Pada pra pembelajaran kategori yang muncul hanya TMI dan SKIT, sedangkan pada pasca pembelajaran sudah mulai muncul kategori SBIT dan IT. Hasil tersebut menunjukkan dengan pelaksanaan program pembelajaran berbasis masalah dapat menumbuhkan keterampilan metakognisi siswa.

Hasil kinerja dalam pelaksanaan pembelajaran berbasis masalah yang dinilai melalui kinerja (lembar observasi) siswa pada pelaksanaan kegiatan praktikum menunjukkan hasil bahwa indikator mengetahui apa yang dibutuhkan untuk belajar dengan baik. 
Indikator tersebut masuk dalam keterampilan metakognisi: planning.

Selain dari hasil penguasaan konsep dan pemecahan masalah, peneliti juga mengamati respon siswa dalam pelaksanaan pembelajaran IPA berbasis masalah. Berdasarkan hasil angket penliaian diri diperoleh perubahan ke arah yang positif pada perubahan kemampuan metakognisi siswa pada saat pelaksanaan praktikum. Pada angket penilaian diri saat praktikum menunjukkan kenaikan indikator metakognisi yang paling tinggi adalah: mengetahui tingkat kemampuan yang telah dimiliki dan membuat ringkasan tentang apa yang telah dipelajari (keterampilan metakognisi: evaluasi), serta menghubungkan informasi yang didapat dengan teori yang ada (keterampilan metakognisi: manajemen informasi).

\section{PENUTUP}

\section{Simpulan}

Berdasarkan hasil-hasil penelitian dan pembahasan dapat disimpulkan sebagai berikut. Pertama, karakteristik program pembelajaran IPA berbasis masalah untuk menumbuhkan metakognisi adalah menggunakan model problem based learning. Indikator-indikator metakognisi yang digunakan adalah mengacu pada tipe-tipe Metakognisi Schraw dan Dennison (1994:472-474) yang meliputi beberapa keterampilan metakognisi: (a) pengetahuan deklaratif, (b) pengetahuan prosedural, (c) pengetahuan kondisional, (d) planning, (e) manajemen informasi, (f) monitoring, (g) debugging dan (h) evaluasi. Kedua, hasil pencapaian keterampilan metakognisi pada aspek tes essay menunjukkan hasil yang positif, pada aspek kinerja menunjukkan indikator plannig yang paling menonjol, sedangkan dari hasil angket menunjukkan dominasi indikator evaluasi.

\section{Saran}

Berdasarkan hasil-hasil yang dicapai pada penelitian ini dapat direkomendasikan sebagai berikut. Perluasan program pembelajaran IPA dengan berbagai model pembelajaran untuk meningkatkan kemampuan metakognisi yang merupakan salah satu dari kemampuan berpikir tingkat tinggi.

\section{E. DAFTAR PUSTAKA}

Arends, Richard. Learning to Teach. Translated by Helly Prajitno Soetjipto. Yogyakarta: Pustaka Pelajar, 2008.

Downing, Kevin. "Problem-Based Learning and Metacognition." Asian Journal Education \& Learning 1 (2010): 75-96.

Flavell, John H. "Speculations about the Nature and Development of Metacognition." In Metacognition, Motivation, and Understanding, 21-29. London: Lawrence Erbaum Associates, 1987.

Rahayu, Putri, S. Mulyani, and S. S. Miswadi. "Pengembangan Pembelajaran IPA Terpadu Dengan Menggunakan Model Pembelajaran Problem Base Melalui Lesson Study." Jurnal Pendidikan IPA Indonesia 1, no. 1 (2012).

Rosidi, Irsad. "PENGEMBANGAN PERANGKAT PEMBELAJARAN IPA TERPADU TIPE INTEGRATED 
UNTUK MENGETAHUI

KETUNTASAN BELAJAR IPA

SISWA SMP PADA TOPIK

PENGELOLAAN LINGKUNGAN."

Jurnal Pena Sains 2, no. 1 (2015):

14-25.

Tandogan, Ruhan Ozkardes, and Akinoglu Orhan. "The Effects of Problem-

Based Active Learning in Science

Education on Students' Academic

Achievement, Attitude and

Concept Learning." Online

Submission 3, no. 1 (2007): 71-81.

Zuhaida, Anggun. "PENGEMBANGAN

ASESMEN METAKOGNISI CALON

GURU IPA MELALUI

PEMBELAJARAN BERBASIS

MASALAH." JURNAL PENELITIAN

12, no. 2 (2015): 213-22. 
10| ibriez $\mid \begin{aligned} & \text { Jurnal Kependidikan Dasar } \\ & \text { Islam Berbasis Sains }\end{aligned}$ Vol 2 No 2 Tahun 2017 